\title{
SOLOS SOB VEGETAÇÃO DE RESTINGA NA ILHA DO CARDOSO (SP). II - MINERALOGIA DAS FRAÇÕES SILTE E ARGILA ${ }^{(1)}$
}

\author{
Felipe Haenel Gomes ${ }^{(2)}$, Pablo Vidal-Torrado ${ }^{(3)}$, Felipe Macías ${ }^{(4)}$, \\ Valdomiro Severino de Souza Júnior ${ }^{(5)}$ \& Xosé Luis Otero Perez ${ }^{(4)}$
}

\begin{abstract}
RESUMO
A vegetação de restinga é uma formação típica que ocorre na costa brasileira em materiais de origem quartzosa e pobres em nutrientes. Os solos que ocorrem nesses ambientes são principalmente Espodossolos e Neossolos Quartzarênicos, com incipiente processo de podzolização. A podzolização é freqüentemente estudada em regiões de clima frio, sendo escassos os estudos mineralógicos de Espodossolos em clima tropical e material de origem quartzoso. Neste trabalho foram estudados solos sob vegetação de restinga na Ilha do Cardoso-SP, com o objetivo de identificar a assembléia mineralógica da fração silte e argila deles, no intuito de dar subsídios para melhor entendimento de sua gênese. Os principais minerais encontrados na fração argila foram quartzo e caulinita e, na fração silte, feldspato e quartzo. Isso indica que nesses solos a assembléia mineralógica é relativamente mais intemperizada do que os Espodossolos encontrados sob clima mais frio, e mesmo em relação a outros solos estudados no litoral brasileiro, devido ao próprio material de origem, pobre em minerais primários intemperizáveis, e à migração de complexos organometálicos insaturados, o que aumenta seu poder de dissolução. Em alguns horizontes (2Cgj) foram identificadas esmectitas, as quais podem ser herdadas ou neoformadas, e sua gênese é dissociada da podzolização.
\end{abstract}

Termos para indexação: Espodossolo, podzolização, minerais primários em solos, caulinita.

\footnotetext{
(1) Extraído de parte da Tese de Doutorado apresentada à Escola Superior de Agricultura "Luiz de Queiroz" - ESALQ/USP. Realizada com auxílio da CAPES e da FAPESP. Recebido para publicação em dezembro de 2005 e aprovado em julho de 2007.

${ }^{(2)}$ Pesquisador do Centro de Tecnologia Canavieira. Fazenda Santo Antonio s/n, Caixa Postal 169, CEP 13400-970 Piracicaba (SP). E-mail:felipehgomes@hotmail.com

((3) Professor do Departamento de Ciência do Solo, ESALQ/USP. Bolsista do CNPq. Email: pablo@esalq.usp.br

(4) Professor do Departamento de Edafologia da Universidade de Santiago de Compostela. Campus Universitário Sur. Faculdade de Bioloxia. Espanha. Email: edfmac@usc.es; edajax@usc.es

${ }^{(5)}$ Professor Adjunto da da Unidade Acadêmica de Serra Talhada/UFRPE. Fazenda Saco s/n, Caixa Postal 063, CEP 56900-000 Serra Talhada (PE). E-mail: valdomiro@uast.ufrpe.br
} 


\title{
SUMMARY: SOILS UNDER RESTINGA VEGETATION ON THE CARDOSO ISLAND (SP). II - MINERALOGY OF SILT AND CLAY FRACTIONS
}

\begin{abstract}
Restinga is a typical vegetation on quartzitic, sandy, nutrient-poor parent materials along the Brazilian coast.. Podzolization is the main pedogenic process in restinga soils and Spodosols and Quartzipsamments with incipient podzolization are the most common soils. Podzolization is frequently studied in cold climate regions, while mineralogical studies of Spodosols in tropical climate on quartzitic parent material are scant. In this work, soils under restinga vegetation on the Ilha do Cardoso-SP, Brazil were studied to identify the mineralogical assembly of silt and clay fractions and to provide a better understanding of their genesis. Quartz and kaolinite are the main minerals in the clay fraction while feldspars and quartz prevail in the silt fraction. This indicates that the mineralogical assembly of the restinga soils on Ilha do Cardoso is poorer than that of soils in colder climates and of other soils along the Brazilian coast. This is mainly due to the parent material which is scarce in easily weatherable primary minerals. In some horizons (2Cgj) smectites were identified; they can be inherited or neoformed, and their genesis is unrelated with podzolization.
\end{abstract}

Index terms: Spodosol, podzolization, primary minerals in soils, kaolinite.

\section{INTRODUÇÃO}

Denomina-se vegetação de restinga uma variedade de formações vegetais, desde herbáceas, passando por formações arbustivas, chegando a florestas cujo dossel não ultrapassa $20 \mathrm{~m}$ de altura (Silva, 1999). Os solos que ocorrem mais comumente sob essa vegetação são Espodossolos e Neossolos Quartzarênicos (Moura Filho, 1998; Gomes et al., 1998; Rossi, 1999); muitas vezes estes últimos apresentam incipiente processo de podzolização.

Os Espodossolos são caracterizados pela presença do horizonte espódico, onde se acumulam misturas de complexos organometálicos, acompanhadas ou não de oxi-hidróxidos de $\mathrm{Fe}$ e $\mathrm{Al}$ e aluminossilicatos com diferentes graus de cristalinidade (imogolita, alofana, haloisita, caulinita e vermiculitas com hidróxi entre camadas) (Estados Unidos, 1999; Embrapa, 1999). São solos que ocorrem em regiões úmidas, predominantemente em climas boreais, sob vegetação florestal, e, em menor freqüência, em regiões de climas menos severos, sobre materiais de origem silicosos (Buurman,1984; Lundström et al., 2000a). Nas regiões tropicais úmidas, ocorrem em materiais de origem quartzosos muito pobres (Oliveira et al., 1992; Lundström et al., 2000b).

A podzolização é o processo que consiste na translocação de material orgânico e Al, acompanhado ou não de $\mathrm{Fe}$, dos horizontes superficiais para o horizonte subsuperficial, formando o horizonte espódico. Anderson et al. (1982) introduziram uma nova hipótese, sugerindo a possibilidade de migração de $\mathrm{Fe}, \mathrm{Al}$ e Si na forma de complexos inorgânicos (protoimogolitas), positivamente carregados. A matéria orgânica coloidal precipitaria depois, ao entrar em contato com esses complexos, formando então o horizonte Bh. Esta hipótese foi refutada por Buurman \& van Reeuwijk (1984), que atribuíram a presença de aluminossilicatos pobremente cristalizados no horizonte $\mathrm{B}$, como a imogolita, à neoformação a partir do Si iluvial junto a espécies de Al liberadas do complexo orgânico pela atividade microbiana.

Segundo Lundström et al. (2000a), são duas as principais teorias sobre mecanismos da podzolização que prevalecem, as quais diferem no mecanismo de imobilização de $\mathrm{Al}$ e Fe no horizonte B. Contudo, é geralmente aceito que, $\mathrm{Fe}$ e $\mathrm{Al}$ migram na forma de compostos orgânicos. A primeira teoria, da adsorção/ precipitação (Petersen, 1976), envolve ácidos orgânicos de peso molecular mais elevado, que dissolvem Fe e $\mathrm{Al}$ de minerais nos horizontes superficiais, formando complexos organometálicos móveis, que, devido à adição contínua de metais, precipitam a uma determinada relação C/Metal (Buurman, 1985), formando o horizonte espódico. A segunda teoria, da biodegradação, envolve ácidos orgânicos de baixa massa molecular, os quais são decompostos microbianamente durante a migração, liberando $\mathrm{Al} \mathrm{e}$ Fe, que precipitam na forma de MTI (materiais do tipo da imogolita) e ferridrita no horizonte B (Lundström et al., 1995).

De acordo com van Breemen \& Buurman (2002), a podzolização altera profundamente os minerais, tanto primários como secundários, havendo enriquecimento relativo de minerais mais resistentes ao intemperismo (quartzo, zircônio e anatásio, dentre outros), enquanto os minerais mais suscetíveis são intemperizados e desaparecem do sistema. A fração argila consistiria em alofana e imogolita, ou em filossilicatos formados por intemperismo in situ.

Estudando a assembléia mineralógica de Espodossolos com diferentes níveis de hidromorfia, 
Haile-Mariam \& Mokma (1995) encontraram, na fração silte, principalmente quartzo e, em menor proporção, feldspato. $\mathrm{Na}$ fração argila, as hidrosseqüências estudadas indicam que ocorreu a transformação de muscovita em vermiculita nos horizontes B e de vermiculita em esmectita nos horizontes E, em cuja fração a esmectita é o mineral dominante. $\mathrm{O}$ intemperismo desses minerais parece ser retardado pelo lençol freático.

No Brasil, Gomes (1995), estudando Espodossolos sob vegetação de restingas no Estado do Rio de Janeiro, encontrou quartzo, feldspatos, caulinita, mica, gibbsita e vermiculita com hidróxi entre camadas na fração silte. Já Moura Filho (1998), estudando Espodossolos sob restinga na costa alagoana, constatou a presença de quartzo, caulinita, feldspatos e mica na mesma fração. No entanto, ressaltou que a composição mineralógica desses solos é muito variável, até mesmo no próprio perfil. Na fração argila, esse autor encontrou caulinita, quartzo, mica, clorita e feldspatoK. Gomes (1995) encontrou nessa fração quartzo, caulinita, mica, gibbsita, vermiculita com hidróxi entre-camadas e esmectita interestratificada. $\mathrm{Na}$ Bahia, Gomes (2002), também em Espodossolos sob vegetação de restinga, encontrou caulinita, quartzo, mica e esmectita.

Este trabalho teve o intuito de identificar os minerais na fração argila e silte de solos sob vegetação de restinga na Ilha do Cardoso-SP, com o objetivo de dar subsídios para melhor entendimento da sua gênese.

\section{MATERIAL E MÉTODOS}

Os solos estudados estão localizados na porção nordeste da Ilha do Cardoso, em uma parcela de 10 ha sob vegetação de restinga, incluída no projeto "BIOTA - parcelas permanentes", pertencente ao parque estadual da Ilha do Cardoso, e descrita por Gomes et al. (2006).

\section{Escolha dos perfis}

A partir dos teores de argila obtidos (Gomes et al., 2006), foram selecionados alguns horizontes para extração da fração argila visando à caracterização mineralógica por meio da difratometria de raios $\mathrm{X}$. Dessa forma, foi obtida esta fração para 16 horizontes, os quais foram analisados, escolhendo-se, ao final, os nove horizontes mais representativos. São eles: perfil H3 (horizontes Cg4 e Cgj8), perfil H9 (horizonte Bhs1), perfil H16 (horizontes Bhsj3 e 2Cgj), perfil C14 (horizontes Bhs1 e Bhs2), perfil J14 (horizonte Bhsj1) e perfil P14 (horizonte 2Cgj).

\section{Preparo das amostras}

As amostras de solos foram submetidas a tratamentos para eliminação da matéria orgânica e lavagem de sais solúveis. Posteriormente, as frações areia, silte e argila foram separadas por peneiramento úmido, sendo silte e argila separados por decantação (Jackson, 1969).

O preparo das amostras foi realizado em lâminas de vidro na forma de agregados orientados no caso das argilas, e na forma de pó não orientado, para o silte. Foram saturadas amostras de argila com $\mathrm{K}^{+}$à temperatura ambiente (K25) e após aquecimento a $350^{\circ} \mathrm{C}(\mathrm{K} 350)$ e $550^{\circ} \mathrm{C}$ (K550), durante três horas. Foi também realizada a saturação com $\mathrm{Mg}^{2+}$ e também as argilas solvatadas em etileno-glicol (MgEG).

A identificação mineralógica foi realizada por difração de raios $\mathrm{X}$ por meio de um difratômetro Philips PW 1130, empregando tensão de $40 \mathrm{KV}$ e corrente de $40 \mathrm{~mA}$, usando a radiação $\mathrm{Cu}-\mathrm{K} \alpha$ ao passo de $0,02^{\circ} 2 \theta$, na velocidade de 1 passo $\mathrm{s}^{-1}$. As amostras de argilas orientadas foram processadas na faixa de 3 a $65^{\circ} 2 \theta$, enquanto as amostras na forma de pó não orientado de argila e silte, no intervalo de 3 a $70^{\circ} 2 \theta$.

Foram também realizados estudos de mineralogia por meio da microscopia eletrônica de varredura (MEV), utilizando microscópio eletrônico LEO 4354 VP na fração densa $(\mathrm{d}>2,89)$ da TFSA (terra fina seca ao ar) dos horizontes 2 Cgj, devido à ocorrência de pirita (Gomes et al., 2006), que é destruída com o tratamento com peróxido de hidrogênio.

\section{RESULTADOS}

\section{Fração silte}

Na fração silte (Figura 1), o quartzo e o feldspato foram os únicos minerais identificados em todos os horizontes, com os picos de 0,426, 0,334 e 0,237 nm para o quartzo e nas regiões de 0,403 a 0,$405 ; 0,374$ a 0,378; e 0,317 a 0,322 para o feldspato. Os horizontes Bhs dos perfis H9 e C14 foram os únicos onde não foi identificada mica. Nos demais perfis, ela foi identificada pelos picos em 1,00; 0,50 e 0,334 nm. O mesmo ocorreu com a caulinita, identificada praticamente nos mesmos horizontes onde ocorreu a mica, excetuando o horizonte Bhs do perfil H9, que apresentou um pico muito sutil, de baixa intensidade, indicando que pode haver traços deste mineral. Para identificação da caulinita, foram utilizados os picos de 0,712 e $0,356 \mathrm{~nm}$.

A microscopia eletrônica de varredura realizada na fração densa $(d>2,89)$ da TFSA mostrou a presença de pirita na fração silte do horizonte 2 Cgj do perfil H16 (Figura 2). É possível identificar também piritas degradadas na fração areia com silicatos incrustados. Na difratometria de raios $\mathrm{X}$, não foi possível identificar a presença desse mineral, provavelmente pelo fato de ele ter sido destruído com o tratamento com peróxido de hidrogênio. 

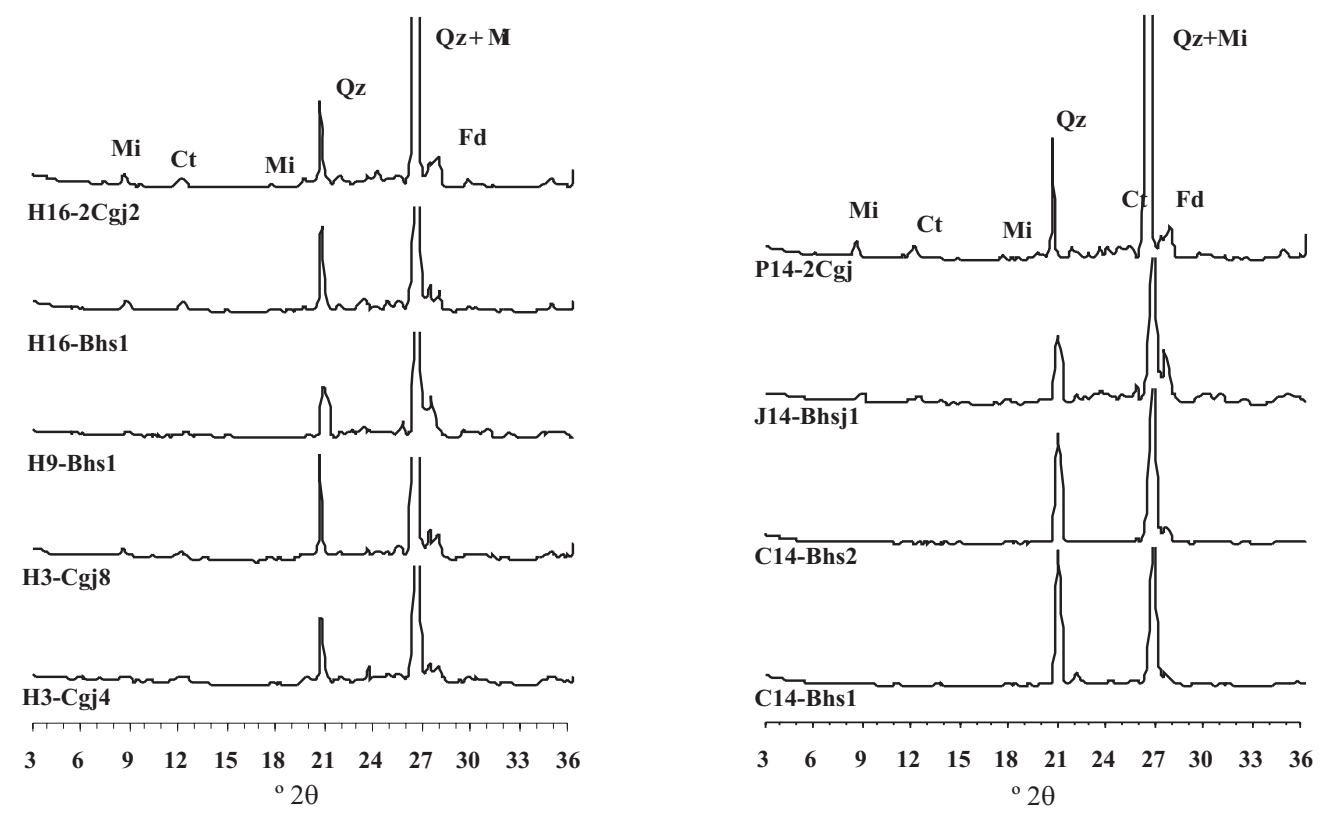

Figura 1. Difratogramas da fração silte dos solos estudados na parcela permanente sob vegetação de mata de restinga do projeto "BIOTA Parcelas Permanentes", Ilha do Cardoso, Cananéia, SP. Ct: caulinita, Mi: mica, Qz: quartzo, Gb: gibbsita, Es: esmectita, Fd: feldspato.
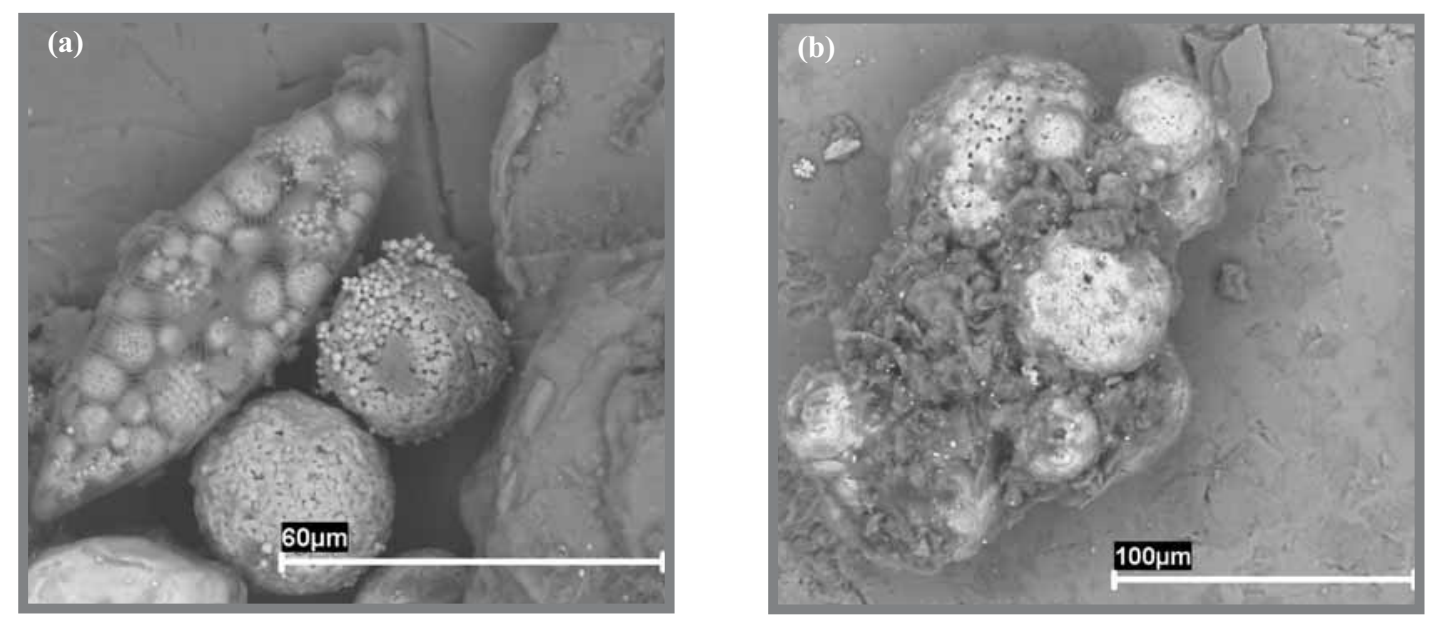

Figura 2. Microscopia eletrônica de varredura (MEV) de piritas na fração silte do horizonte $2 \mathrm{Cgj} 2 \mathrm{do}$ perfil H16, mostrando um exoesqueleto de diatomácea preenchido com o mineral (a) e outra, em processo de oxidação com silicatos incrustados ao redor $(b)$.

\section{Fração argila}

Os minerais comuns a todos os horizontes na fração argila foram o quartzo, identificado nos picos de 0,426 , 0,334 e 0,237 nm, e a caulinita, por meio dos picos de 0,712 e $0,356 \mathrm{~nm}$, os quais colapsaram ao serem submetidos à temperatura de $550^{\circ} \mathrm{C}$ (Figuras $3,4 \mathrm{e}$ 5). Nos horizontes Bhs1 e Bhs2 do perfil C14, destacase a presença de vermiculita, identificada no pico de $1,40 \mathrm{~nm}$, o qual não expandiu ao ser saturado com etileno-glicol (EG) e colapsou a $550{ }^{\circ} \mathrm{C}$, bem como a ausência de mica, identificada nos picos de 1,00, 0,50 e $0,334 \mathrm{~nm}$ nos outros perfis. Outro mineral 2:1 identificado foi a esmectita, nos horizontes $2 \mathrm{Cgj}$ dos perfis $\mathrm{H} 16$ e P14, com o pico de 1,40 nm, que expandiu para 1,68 ao saturar a amostra com EG. Este mineral ocorreu também no perfil H3, nos horizontes $\mathrm{Cg} 4$ e Cgj8. A gibbsita ocorreu nos perfis H3, H9, J14 e $\mathrm{P} 14$, sendo identificada no pico de $0,483 \mathrm{~nm}$, colapsando à temperatura de $350^{\circ} \mathrm{C}$.

\section{DISCUSSÃO}

De forma geral, os minerais encontrados, tanto na fração silte como na argila, correspondem àqueles 

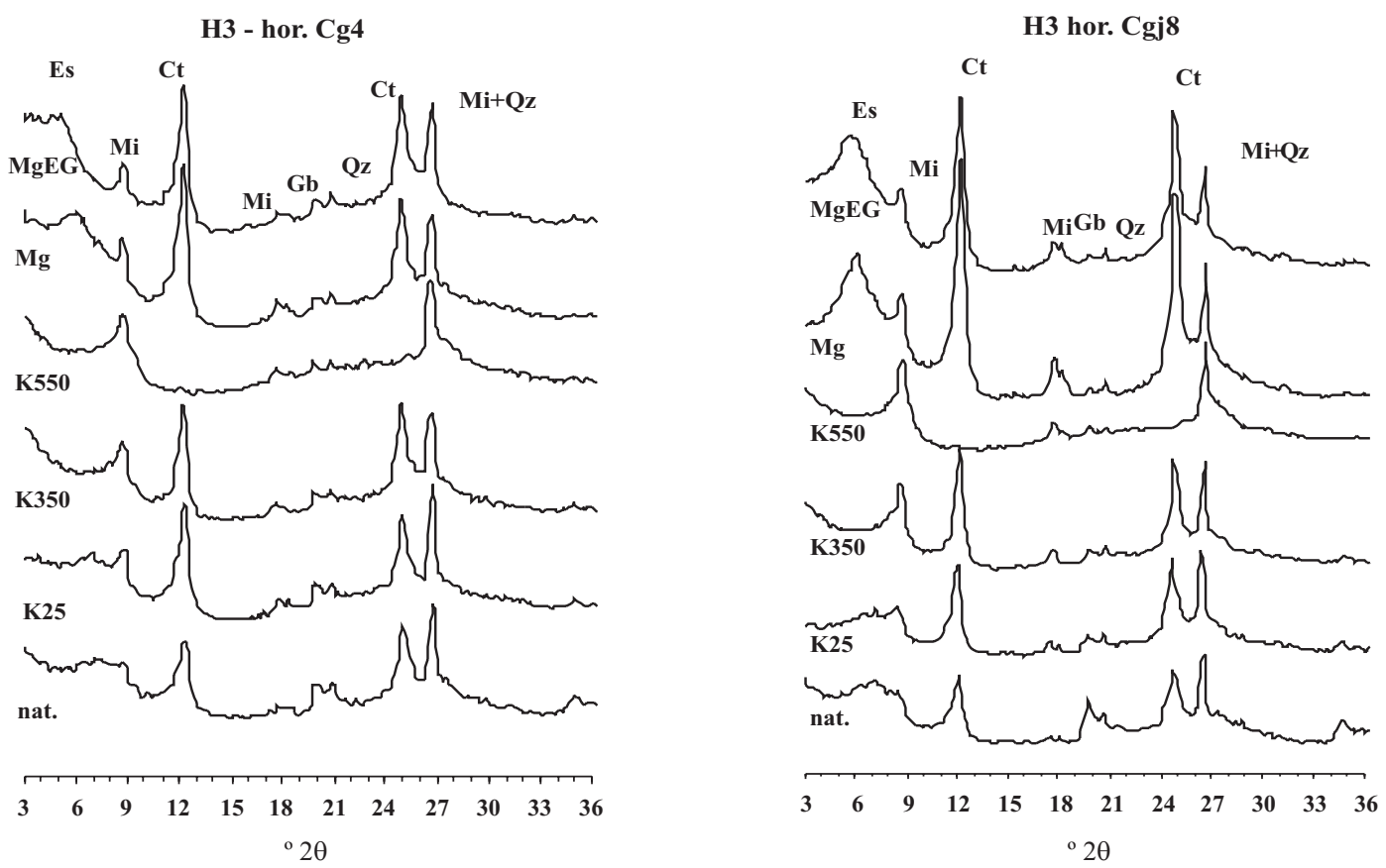

Figura 3. Difratogramas da fração argila dos horizontes Cg4 e Cgj8 do perfil H3. Ct: caulinita, Mi: mica, Qz: quartzo, Gb: gibbsita, Es: esmectita.

observados em outros estudos em solos sob vegetação de restinga no Brasil. As principais diferenças são a ausência de vermiculita com hidróxi entre camadas, descrita por Gomes (1995) nas restingas do Estado do Rio de Janeiro, e de clorita, identificada por Moura Filho (1998) na costa alagoana.

$\mathrm{Na}$ fração silte, foram identificados quartzo e feldspatos em todos os solos. A ocorrência de diferentes faixas de picos de feldspatos pode indicar a presença tanto de feldspatos potássicos como de plagioclásios. Estes minerais foram provavelmente herdados do intemperismo de rochas cristalinas da Serra do Mar ou de areias reliquiais dos sedimentos arenosos costeiros retrabalhados durante os últimos eventos transgressivos holocênicos.

Nos perfis H9 e C14 não foi identificada a presença de mica na fração silte, provavelmente devido à ocorrência de condições não favoráveis à sua estabilidade nesta fração, já que o material de origem é o mesmo, ocorrendo na fração argila apenas no perfil H9. Desses dois perfis, no C14 não foi identificada mica nem mesmo na fração argila, ocorrendo, contudo, a vermiculita, o que pode indicar possível transformação de mica em vermiculita, principalmente no horizonte Bhs2. De acordo com Gomes et al. (2006), esses dois perfis, embora hidromórficos, são os que têm menor influência do lençol freático dentre os solos estudados, o que provavelmente pode influenciar a maior intensidade do intemperismo.

A presença de quartzo na fração argila em todos os horizontes é comum em Espodossolos, sendo reportada por diversos autores, estudando desde solos sob clima frio, sobre diferentes materiais de origem, até aqueles que ocorrem em sedimentos arenosos, típicos de regiões tropicais (Guillet et al., 1975; Johnson \& McBride, 1989; He et al., 1998; Gustafsson et al., 1999; Gomes, 1995; Moura Filho, 1998; Melkerud et al., 2000; Gomes, 2002). Segundo Mc Keague et al. (1983), é comum a presença deste mineral em Espodossolos de clima temperado desenvolvidos no Quaternário. Drees et al. (1989) citaram a ocorrência de quartzo na fração argila, sendo restrita à fração argila grossa $(0,2 \mathrm{a} 2 \mu \mathrm{m})$.

A caulinita ocorreu em todos os solos na fração argila, fato comum em Espodossolos de clima tropical e subtropical, onde o intemperismo é mais intenso, podendo ser o mineral dominante (Van Breemen \& Buurman, 2002). De acordo com Kämpf \& Curi (2003), a caulinita pode ser formada a partir de diversos minerais - o exemplo neste estudo poderia ser a partir dos feldspatos, os quais ocorrem na fração silte. Também, já seria herdada dos solos das áreas do entorno, que são essencialmente cauliníticos e gibbsíticos (Sakai \& Lepsch, 1984). A caulinita na fração silte é possivelmente originada da intemperização de biotita (Kretzschmar et al., 1997; Jolicoeur et al., 2000) ou da muscovita (Muggler, 1998).

A esmectita que foi identificada nos perfis $\mathrm{H} 16$, P14 e H3 pode ser de origem alóctone ou neoformada, não tendo relação com o processo de podzolização. Neoformação de esmectitas nesse ambiente seria possível por meio da oxidação de pirita, formando nontronita ou esmectita férrica, desde que houvesse disponibilidade de Si e Al (Fernández-Caliani et al., 2004). A degradação da pirita (Gomes et al., 2006) e a 
H9 hor. Bhs1

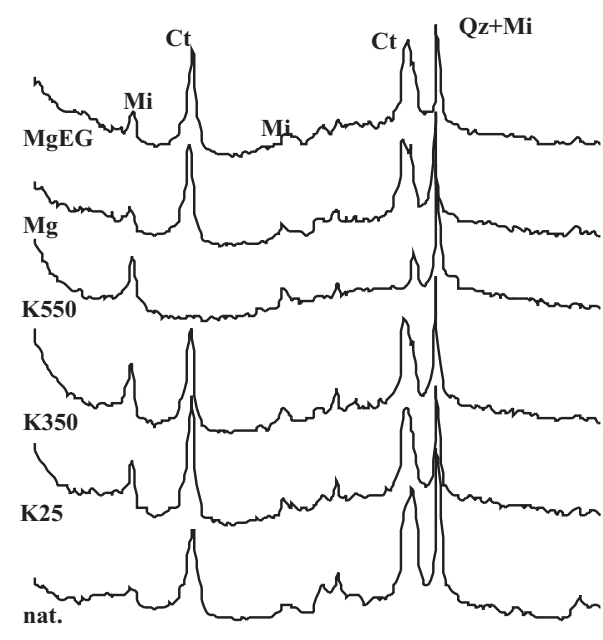

H16 hor. Bhsj3

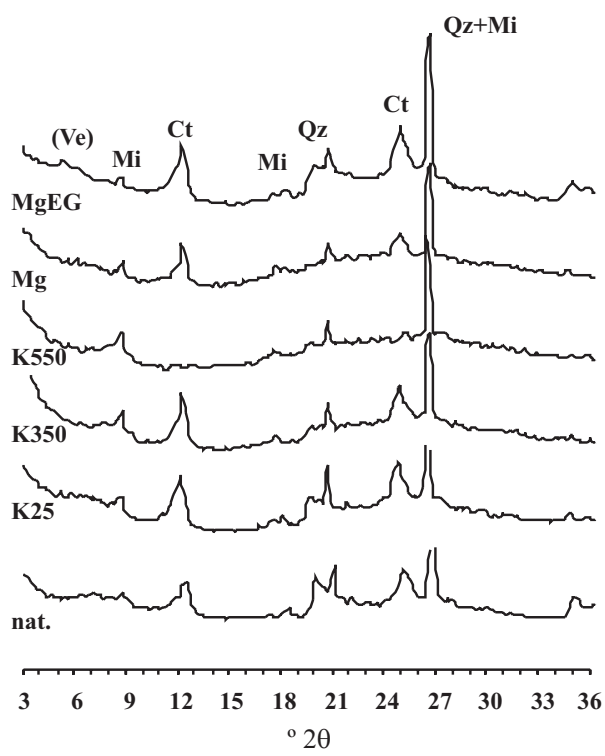

J14 hor. Bhsj1

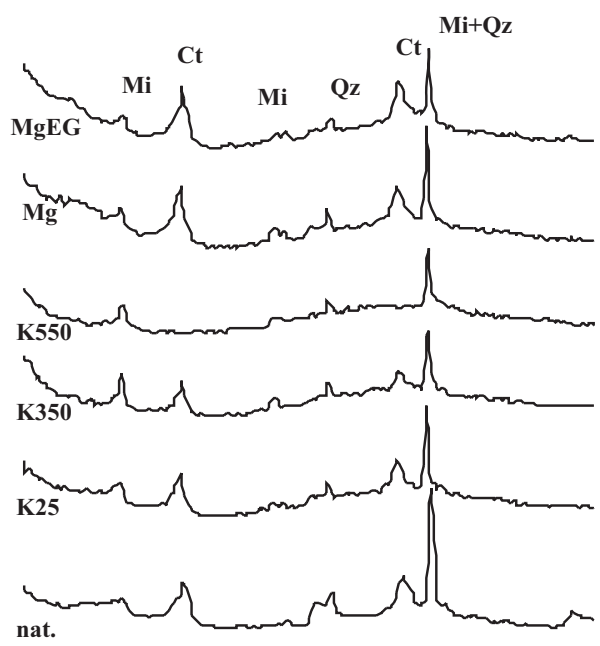

H16 hor. 2Cgj2

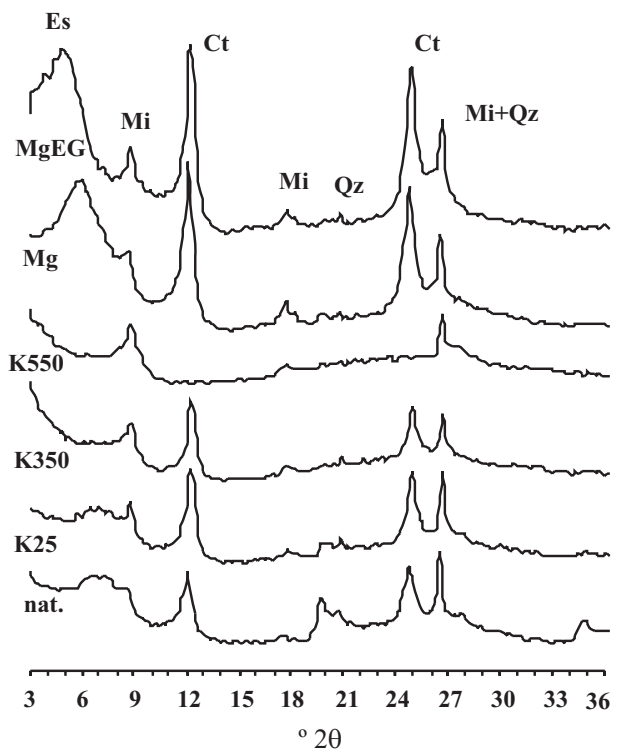

Figura 4. Difratogramas da fração argila do horizonte Bhs1 do perfil H9, horizonte Bhsj1 do perfil J14 e dos horizontes Bhsj3 e 2Cgj2 do perfil H16. Ct: caulinita, Mi: mica, Qz: quartzo, Gb: gibbsita, Es: esmectita, Ve: vermiculita.

presença de diatomáceas nos horizontes onde ocorreu a esmectita (Figuras 2 e 3 ) podem apoiar essa hipótese. Todavia, não se pode deixar de ressaltar outra possível origem, marinha, já que este horizonte corresponde a um nível estratigráfico inferior de textura mais fina, com argilas depositadas em um pretérito fundo de canal ou de baía, sobre o qual as areias holocênicas foram depositadas. A origem continental deve ser descartada, já que é rara a ocorrência de solos no entorno da planície com presença de esmectita (Sakai \& Lepsch, 1984). No caso do perfil $\mathrm{H} 3$, onde não foi identificada a presença de horizonte 2 Cgj, a esmectita pode ocorrer devido à transformação a partir da mica, com a contribuição de $\mathrm{Fe}^{3+}$ da oxidação da pirita, que, apesar de não identificada por DRX, deve ocorrer em horizontes mais profundos, influenciando os horizontes suprajacentes.

A presença de gibbsita se deu principalmente nos horizontes $2 \mathrm{Cgj}$. O perfil H3 também apresentou esse mineral, sendo mais um indício de influência de material de origem relacionado aos horizontes $2 \mathrm{Cgj}$. Este mineral também pode ter sido herdado a partir de solos das áreas do entorno, como comentado anteriormente para a caulinita. Os dados químicos, como o abaixamento do $\mathrm{pH}$ determinado na TFSA e o incremento dos teores de $\mathrm{S}$, e o aumento do teor de argila e silte, em profundidade neste perfil, corroboram essa hipótese (Gomes et al., 2006). 
Mesmo com a forte influência do lençol freático, a pobreza inicial do material de origem, o qual sofreu retrabalhamentos nos dois últimos eventos transgressivos (Suguio \& Martin, 1978), gerou solos com assembléia mineralógica menos diversificada que as daqueles de regiões temperadas e até mesmo de outros estudos realizados sob vegetação de restinga no Brasil. A composição mineralógica da fração silte em relação à fração argila é um bom indício de que os poucos minerais menos resistentes que ocorreram nesta fração, como o feldspato e a mica, deram lugar à caulinita e vermiculita.

\section{C14 hor. Bhs1}

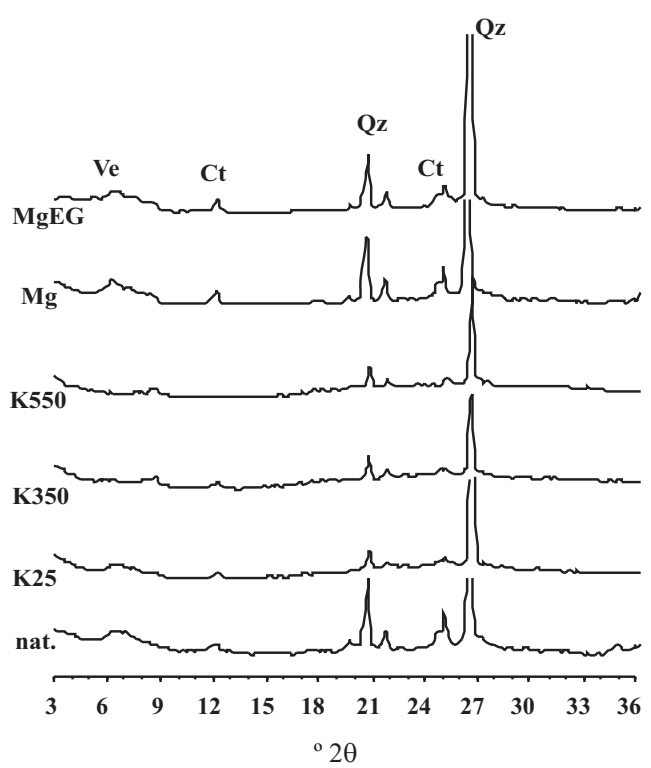

A predominância de fases não-cristalinas ocorreu em todos os solos estudados, como descrito em Gomes (2005), com as extrações por ditionito-citrato (DC) obtendo valores próximos aos das extrações com oxalato de amônio e pirofosfato de sódio. Contudo, cabe ressaltar que os valores extraídos de sílica pelas dissoluções seletivas (dados não apresentados) foram abaixo do limite de detecção pelos métodos utilizados em todos os horizontes espódicos, mesmo no extrato sem diluição, eliminando ou diminuindo substancialmente a possibilidade de ocorrência de silicatos mal cristalizados, como as proto-imogolitas e

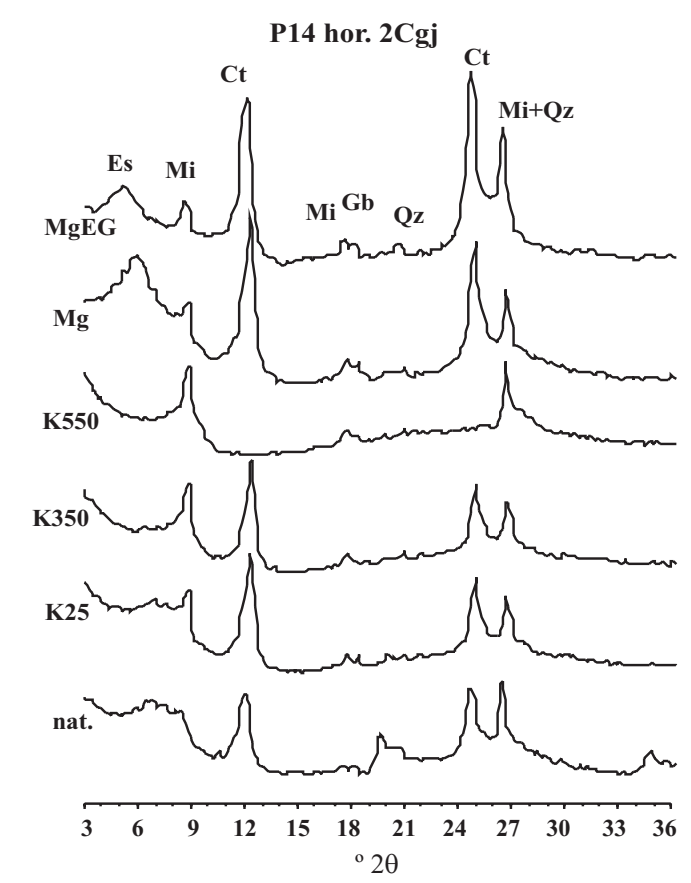

Figura 5. Difratogramas dos horizontes Bhs1 e Bhs2 do perfil C14 e do horizonte 2Cgj do perfil P14. Ct: caulinita, Mi: mica, Qz: quartzo, Gb: gibbsita, Es: esmectita, Ve: vermiculita. 
a alofana nesses horizontes. Para estudo mais pormenorizado das fases amorfas que ocorrem nesses solos, devem-se utilizar, em adição à difração de raios $X$, técnicas mais sofisticadas, como a espectroscopia no infravermelho transformada de Fourier, para as fases contendo Al, e espectroscopia de Mössbauer, para as fases contendo Fe.

\section{CONCLUSÕES}

1. Os horizontes espódicos apresentaram quartzo e caulinita como principais minerais da fração argila e quartzo e feldspato na fração silte.

2. A esmectita nos horizontes 2 Cgj tem duas origens possíveis: neoformação de nontronita ou esmectitas férricas a partir da oxidação da pirita e, ou, herança do material de origem marinha e não tem relação com o processo de podzolização.

3. O intenso intemperismo, aliado à pobreza do material de origem, gerou solos com assembléia mineralógica menos diversificada em relação aos Espodossolos de clima temperado.

\section{AGRADECIMENTOS}

À Coordenação de Aperfeiçoamento de Pessoal de Nível Superior (CAPES), pelo financiamento do doutorado-sanduíche do primeiro autor; e à FAPESP, por meio do projeto: "Diversidade, dinâmica e conservação em florestas do Estado de São Paulo: 40 ha de parcelas permanentes- BIOTA", pelo apoio financeiro.

\section{LITERATURA CITADA}

ANDERSON, H.A.; BERROW, M.L.; FARMER, V.C.; HEPBURN, A.; RUSSELL, J.D. \& WALKER, A.D. A reassessment of Podzol forming processes. J. Soil Sci., 33:125-136, 1982.

BUURMAN, P. Carbon/ sesquioxide ratios in organic complexes and the transition albic-spodic horizon. J. Soil Sci., 36:355260,1985 .

BUURMAN, P. Editor's comments on paper 1- The Podzol concept. In: BUURMAN, P. Podzols. New York, Van Nostrand Reinhold, 1984. p.8-11.

BUURMAN, P. \& van REEUWIJK, L.P. Proto-imogolite and the process of Podzol formation: A critical note. J. Soil Sci., 35:447-452, 1984.

DREES, L.R.; WILDING, L.P.; SMECK, N.E. \& SENKAYI, A.L. Silica in soils: Quartz and disordered silica plymorphs. In: DIXON, J.B. \& WEED, S.B. Minerals in soil environments. 2.ed. Madison, Soil Science Society of America, 1989. p.913-974.
EMPRESA BRASILEIRA DE PESQUISA AGROPECUÁRIA EMBRAPA. Centro Nacional de Pesquisa de Solos. Sistema brasileiro de classificação de solos. Rio de Janeiro, Centro Nacional de Pesquisa de Solos, 1999. 412p.

ESTADOS UNIDOS. Department of Agriculture. Soil Survey Division. Soil Conservation Service. Soil Survey Staff. Soil taxonomy: A basic system of soil classification for making and interpreting soil surveys. 2.ed. Washington, 1999. $869 \mathrm{p}$.

FERNANDEZ-CALIANI, J.C.; CRESPO, E.; RODAS, M.; BARRENECHEA, J.F. \& LUQUE, F.J. Formation of nontronite from oxidative dissolution of pyrite disseminated in precambrian felsic metavolcanics of the Southern Iberian Massif (Spain). Clays Clay Miner., 52:106-114, 2004.

GOMES, F.H. Caracterização de solos de manguezais e de restinga no município de Ilhéus-Bahia. Viçosa, MG, Universidade Federal de Viçosa, 2002. 96p. (Tese de Mestrado)

GOMES, F.H. Caracterização e gênese de solos sob vegetação de restinga na Ilha do Cardoso-SP. Piracicaba, Escola Superior de Agricultura "Luiz de Queiroz", 2005. 107p. (Tese de Doutorado)

GOMES, F.H.; VIDAL-TORRADO, P.; MACÍAS, F.; GHERADI, B. \& OTERO, X.L. Solos sob vegetação de restinga na Ilha do Cardoso (SP): I. Caracterização e classificação. R. Bras. Ci. Solo, 31:1563-1580, 2007.

GOMES, J.B.V. Caracterização, gênese e uso de solos de três sítios de restinga sob diferentes coberturas vegetais no Estado do Rio de Janeiro. Viçosa, MG, Universidade Federal de Viçosa, 1995. 158p. (Tese de Mestrado)

GOMES, J.B.V.; RESENDE, M.; REZENDE, S.B. \& MENDONÇA, E.S. Solos de três áreas de restinga. I. Morfologia, caracterização e classificação. Pesq. Agropec. Bras., 33:1907-1919, 1998.

GUILLET, B.; ROUILLER, J. \& SOUCHIER, B. Podzolization and clay migration in Spodosols of Eastern France. Geoderma, 14:223-245, 1975 .

GUSTAFSSON, J.P.; BHATTACHARYA, P. \& KARLTUN, E. Mineralogy of poorly crystalline aluminum phases in the B horizon of Podzols in Southern Sweden. Appl. Geochem., 14:707-718, 1999.

HAILE-MARIAM, S. \& MOKMA, D.L. Mineralogy of two sandy Spodosol hydrosequences in Michigan. Soil Survey Horizons, 36:117-162, 1995.

HE, J.Z.; GILKES, R.J. \& DIMMOCK, G.M. Mineralogical properties of sandy Podzols on the Swan Coastal Plain, South-west Australia, and the effects of drying on their phosphate sortion characteristics. Austr. J. Soil Sci., 36:395-409, 1998

JACKSON, M.L. Soil chemical analysis - Advanced course. Madison, University of Wisconsin, 1969. 895p.

JOHNSON, M.G. \& MCBRIDE, M.B. Mineralogical and chemical characteristics of Adirondack Spodosols: Evidence for para- and noncrystalline aluminosilicate minerals. Soil Sci. Soc. Am. J., 56:482-490, 1989. 
JOLICOEUR, S.; ILDEFONSE, P. \& BOUCHARD, M. Kaolinite and gibbsite weathering of biotite within saprolites and soils of central Virginia. Soil Sci. Soc. Am. J., 64:11181129,2000

KÄMPF, N. \& CURI, N. Argilominerais em solos brasileiros. In: CURI, N.; MARQUES, J.G.S.M.; GUILHERME, L.R.G.; LIMA, J.M.; LOPES, A.S. \& ALVAREZ V., V.H., eds. Tópicos em ciência do solo. Viçosa, MG, Sociedade Brasileira de Ciência do Solo, 2003. v.3. p.1-54.

KRETZSCHMAR, R.; ROBARGE, W.P.; MOOZEGAR, A. \& VEPRASKAS, M.J. Biotite alteration to halloysite and kaolinite in soil-saprolite profiles developed from mica schist and granite gneiss. Geoderma, 75:155-170, 1997.

LUNDSTRÖM, U.S.; van BREEMEN, N. \& BAIN, D.C. The podzolization process: A review. Geoderma, 94:91-107, $2000 \mathrm{~b}$.

LUNDSTRÖM, U.S.; van BREEMEN, N. \& JONGMANS, A.G. Evidence for microbial decomposition of organic acids during podzolization. Eur. J. Soil Sci., 46:489-496, 1995.

LUNDSTRÖM, U.S.; van BREEMEN, N.; BAIN, D.C.; van HEES, P.A.W.; GIESLER, R.; GUSTAFSSON, J.P.; ILVESNIESMI, H.; KARLTUN, E.; MELKERUD, P.A.; OLSSON, M.; RIISE, G.; WAHLBERG, O.; BERGELIN, A.; BISHOP, K.; FINLAY, R.; JONGMANS, A.G.; MAGNUSSON, T.; MANNERKOSKI, H.; NORDGREN, A.; NYBERG, L.; STARR, M. \& TAU STRAND, L. Advances in understanding the podzolization process resulting from a multidisciplinary study of three coniferous forest soils in the Nordic Countries. Geoderma, 94:335-353, 2000a.

McKEAGUE, J.A.; DeCONINCK, F. \& FRANZMEIER, D.P. Spodosols. In: WILDING, L.P.; SMECK, N.E. \& HALL, G.F. Pedogenesis and soil taxonomy. II The soil orders. Amsterdam, Elsevier, 1983. p.217-252.

MELKERUD, P.A.; BAIN, D.C.; JONGMANS, A.G. \& TARVAINEN, T. Chemical, mineralogical and morphological characterization of three Podzols developed on glacial deposits in Northern Europe. Geoderma, 94:125-148, 2000.
MOURA FILHO, G. Caracterização e uso de solos arenosos associados à foz do rio São Francisco, no litoral sul de Alagoas. Viçosa, MG, Universidade Federal de Viçosa, 1998. 169p. (Tese de Doutorado)

MUGGLER, C.C. Polygenetic Oxysols on Tertiary surfaces, Minas Gerais, Brazil. Soil genesis and landscape development. Wageningen, Wageningen University, 1998. 186p. (Tese de Doutorado)

OLIVEIRA, J.B.; JACOMINE, P.K.T. \& CAMARGO, M.N. Classes gerais de solos do Brasil: Guia auxiliar para seu reconhecimento. 2.ed. Jaboticabal, FUNEP, 1992. 201p.

PETERSEN, L. Podzols and podzolization. Copenhagen, Royal Veterinary and Agricultural University, 1976.293p. (Tese de Doutorado)

ROSSI, M. Fatores formadores da paisagem litorânea: A bacia do Guaratuba, São Paulo - Brasil. São Paulo, Universidade de São Paulo, 1999.159p. (Tese de Doutorado)

SAKAI, E. \& LEPSCH, I.F. Levantamento pedológico detalhado da estação experimental de Pariqüera Açú. Campinas, Instituto Agronômico, 1984. 56p. (Boletim Técnico, 83)

SILVA, S.M. Diagnósticos das restingas do Brasil. In: WORKSHOP DE AVALIAÇÃO E AÇÕES PRIORITÁRIAS PARA CONSERVAĈ̃O DA BIODIVERSIDADE DA ZONA COSTEIRA E MARINHA, 1999, Porto Seguro. Anais eletrônicos. Porto Seguro, Fundação BIO RIO, 1999. Disponível em: <http://www.bdt.fat.org.br/workshop/ costa/restinga/> . Acesso em: 10 de abril de 2002.

SUGUIO, K. \& MARTIN, L. Formações quaternárias marinhas do litoral paulista e sul fluminense. In: INTERNATIONAL SYMPOSIUM ON COASTAL EVOLUTION IN THE QUATERNARY, 1., São Paulo, 1978. Anais. São Paulo, IGUSP, 1978. 55p.

van BREEMEN, N. \& BUURMAN, P. Soil formation. 2.ed. Dordrecht, Kluwer Academic Publishers, 2002. 404p. 